\title{
PERCEPÇÃO DE IDOSOS SOBRE OS IMPACTOS DA PANDEMIA NAS POLÍTICAS E AÇÕES DIRECIONADOS AO ENVELHECIMENTO
}

Luiz Gustavo Fernandes da Rosa; Universidade Luterana do Brasil - Canoas/RS; enfermeiro.luizgustavofr@outlook.com

Nádia Teresinha Schroder; Universidade Luterana do Brasil - Canoas/RS; propos@ulbra.br Ana Maria Pujol Vieira dos Santos; Universidade Luterana do Brasil - Canoas/RS; anapujol@ulbra.br

\section{RESUMO}

Introdução: A pandemia do coronavirus trouxe desafios ao envelhecimento populacional, atingindo um número significativo de pessoas e exigindo mudanças repentinas para o seu controle. Em 2017 o município de Canoas (RS) foi reconhecido pelo Ministério da Saúde, como referência nacional no cuidado e acolhimento de idosos. Diante disso, é relevante o conhecimento do olhar dos idosos em relação a este novo contexto de inserção das políticas e ações direcionadas ao envelhecimento. Objetivo: Conhecer a percepção dos idosos sobre os impactos da pandemia nas políticas e ações direcionados ao envelhecimento em Canoas. Métodos: Estudo de abordagem qualitativa, descritiva e transversal, com uma amostra de 12 idosos que foram submetidos a entrevistas semiestruturadas. As falas foram gravadas, transcritas e analisadas conforme o método de análise de conteúdos proposto por Minayo (2014). Resultados: Foram levantadas quatro categorias: Conceito de política pública; Reconhecimento da existência de políticas públicas voltadas ao envelhecimento; Transformações e desafios impostos pela pandemia; Avanços e oportunidades na pandemia. Conclusão: As políticas públicas são vistas como oferta de ajuda em saúde. O conceito ainda esteve relacionado ao entendimento político partidário, à discriminação da velhice e reduzida participação social. Os idosos reconhecem ações para o envelhecimento ativo e saudável, porém, ressaltam inefetividade diante do desinteresse social. A pandemia transformou os modos de viver, as ações e políticas para o envelhecimento, havendo incertezas para o futuro. Contudo, percebem avanços na organização e atendimento pelos serviços, que devem ser estendidos ao setor público, sendo este também, momento oportuno para o autocuidado em saúde.

Palavras-chave: Dinâmica populacional; Envelhecimento; Política Pública; Pandemias.

Agradecimentos: O presente trabalho foi realizado com o apoio da Coordenação de Aperfeiçoamento de Pessoas de Nível Superior - Brasil (CAPES) - Código de Financiamento 001. 